\title{
El lenguaje y los personajes en la creación del legendarium en la narrativa de J. R. R. Tolkien
}

\author{
Language and characters in the creation of the legendarium \\ in the narrative of I. R. R. Tolkien
}

\section{Joyzukey Armendáriz Hernández}

ORCID: 0000-0002-9574-7101/joyzukey.armendarizhrdz@uanl.edu.mx

Doctorado en Filosofía, Facultad de Filosofía y Letras (FFYL) Universidad Autónoma de Nuevo León (UANL)

RESUMEN

El presente artículo bosqueja el contexto de creación del legendarium de J. R. R. Tolkien, a través de las ejemplificaciones del lenguaje, los personajes mitológicos y la manera en que éstos se interrelacionan en las obras sobre la Tierra Media. El lenguaje posibilita la construcción de los fundamentos de la ideología de Tolkien, a lo cual se suman los personajes mitólogicos que conforman el universo creado por este autor. Este universo se muestra más visiblemente en las obras de El Señor de los Anillos y El Silmarilion. El artículo inicia con una breve biografía de Tolkien, además de la cronología de publicación de sus obras, que se van complementando entre sí. La manera de narrar de Tolkien elabora el sustento de la construcción total de un mundo nuevo sostenido por sus personajes y su lenguaje.

\section{PALABRAS CLAVE}

J. R. R. Tolkien, legendarium, Señor de los Anillos,

Silmarilion, valar

\section{ABSTRACT}

This article outlines the context for the creation of J. R. R. Tolkien's legendarium, through exemplifications of language, mythological characters, and the way they interrelate in the works about Middle-Earth. Language enables the construction of the foundations of Tolkien's ideology, to which the mythological characters that make up the universe created by this author are added. This universe is most visibly shown in the works of The Lord of the Rings and The Silmarilion. The article begins with a brief biography of Tolkien, in addition to the publication chronology of his works, which complement each other. Tolkien's way of narrating provides the basis for the total construction of a new world sustained by its characters and their language.

KEY WORDS

J. R. R. Tolkien, legendarium, The Lord of the Rings, Silmarilion, valar 
John Ronald Reuel Tolkien (1892-1973) fue un filólogo y reconocido académico medievalista, profesor especializado en inglés antiguo, quien ocupó esta posición en Oxford de 1925 a 1945. Su trabajo, entre otros temas, exploraba correlaciones entre mitos y creencias de la cultura anglosajona, que observaba como fundamentales para el ser humano (Jakobsson, 2009). Desde pequeño mostró interés en distintos lenguajes. Leía fluidamente latín, español, francés y alemán. A los 18 años, coinventaría el lenguaje nevbosh, traducido como "nuevo disparate", al no tener un sentido específico en particular. En sus años académicos, este contexto le resultaría fructífero, al añadir nuevo conocimiento en finlandés, gótico y galés a la creación de su lenguaje élfico (Jakobsson, 2009).

El corpus del autor enmarca los relatos de la Tierra Media, el lugar de creación donde los dioses, obedientes al deseo del único dios, formaron sabios o ángeles, elfos de belleza incomparable, valientes enanos, hombres honorables y árboles ancestrales; también había cabida ahí para terribles orcos, arañas gigantes, balrogs - demonios de fuego-y encarnaciones de maldad, como Melkor y Sauron. Estos relatos fueron publicados parcialmente en vida del autor, y póstumamente, por parte de su hijo, Christopher Tolkien.

El reconocido místico Henry Corbin presenta el concepto de imaginal (Herrero-Gil, 2008), que se refiere a lo que existe en el mundo espiritual y luego toma cuerpo, así como, a la inversa, al cuerpo que se torna espiritual en un ciclo incesante. De esta manera, la criatura puede tener comunicación con lo Absoluto. Aunque la idea de Corbin se conecta con el concepto de imaginario, propongo que este proceso de instauración de un imaginario es necesario dentro de la narrativa de Tolkien para fortalecer la noción del legendarium, término usado por Tolkien para describir su mitología sobre la Tierra Media.

Así es posible explicar la creación de los dioses de la Tierra Media, los valar, que por instrucción de Eru lllúvatar, el dios supremo, transforman este lugar, completando la creación y son fuente de sabiduría para los elfos. Esto se relaciona con la imaginación activa o creadora que Corbin explica, lo cual también se fortalece en la complementación de las historias, ya sea en los apéndices de EI Señor de los Anillos (en adelante SDLA), EI Silmarilion o Los cuentos inconclusos de Númenor y la Tierra Media. De esta manera, la construcción del mito y del imaginario que Tolkien realiza se liga con un texto nuevo que emerge de esta construcción, que es visiblemente diferente de aquellos de los que toma referencia.

La obra SDLA narra las aventuras de la Comunidad del Anillo para lograr la destrucción del Anillo y así vencer al Señor Oscuro, Sauron, lugarteniente de Melkor en las edades antiguas y ahora encarnanción de la maldad en Arda. En esta narración se comienza a dar preeminencia al papel de los hombres, sin eliminar la jerarquía e importancia de los elfos. La historia termina con el reestablecimiento de la línea real de los hombres de antaño, llamados númenóreanos, y de Aragorn, quien se convierte en el primer rey del Reino Unificado de Gondor y Arnor. Así inicia la Cuarta Edad del Sol.

Año 17, núm. 41, marzo 2021

ISSN: 2007-1760 (impreso) 2448-9026 (digital) | DOI: 10.30973/inventio/2021.17.41/4 
Para este artículo, se contextualizarán dos obras principales de Tolkien: SDLA, publicada en inglés y que contiene tres volúmenes: La Comunidad del Anillo, Las dos torres y El retorno del rey, y El Silmarilion, editada y publicada póstumamente, en 1977, por Christopher Tolkien (1924-2020). Esta segunda obra, El Silmarilion, ofrece una gran oportunidad de análisis y nuevos enfoques. Tradicionalmente, el mayor peso analítico de la obra de Tolkien se ha puesto en SDLA, una obra que ha sido revisada desde diversas perspectivas a partir de su publicación. Al ser El Silmarilion una obra que escapa ligeramente a la época de su autor se ha minimizado su importancia; sin embargo, la visión mayor del legendarium está descrita en ella, lo que nos permite ahondar en esta noción.

El legendarium comienza en el relato de El Hobbit, publicado en 1937 como obra singular, sin considerar una secuela. No obstante, al recibir buenas críticas y convencido por su editorial, Tolkien decidió trabajar la secuela de esta obra con un tono más oscuro, es decir, ya no enfocado como una historia para niños sino para adultos (Shippey, 2000). El anillo que Bilbo había guardado inocentemente por décadas tendría al fin su desarrollo.

De manera paralela a la creación de SDLA, Tolkien desarrolla más profundamente el legendarium en El Silmarilion, con la esperanza de que ambas obras se publicaran simultáneamente y la historia resultase más clara para los lectores, ya que SDLA contiene múltiples referencias a los mitos de la creación de la Tierra Media, los personajes que participaron en incontables guerras antiguas y, por supuesto, el origen del mal, encarnado en Sauron, el Señor Oscuro. A pesar de este deseo, que Tolkien consideraba una necesidad, la casa editorial George Allen \& Unwin desestimó la solicitud del autor. Debido a esta negativa, Tolkien rechazó inicialmente la oferta de publicación, aunque acabó por aceptarla, ya que ninguna otra casa editorial estaba dispuesta a publicar una novela del género que luego se conocería como alta fantasía (Shippey, 2000).

Lo anterior provocaba complicaciones en la coherencia de la trama que se presenta en SDLA, por lo que Tolkien agregó apéndices (A-F) para subsanar estos espacios (Tolkien, 2012). En tales secciones, el autor explora la historia de la línea real de los númenóreanos, a los cuales pertenece Aragorn y cuya característica principal es su longevidad; también describe las edades anteriores con sus guerras, a modo de anales del reino, árboles genealógicos de los personajes incluidos en La Comunidad del Anillo, calendarios y nombres de meses que divergen del gregoriano, y explicaciones del uso del "lenguaje común" usado por los personajes, lo cual da espacio a explicaciones lingüísticas acerca de cualquier otro idioma incluido en la historia. No obstante, pareciera que estos apéndices guardan una similitud con los libros apócrifos incluidos al final de la Biblia conocida como Vulgata Sixtina, según rescatan algunos historiadores (Pagán, 2017), lo cual busca aumentar la realidad del legendarium sobre estos "detalles ocultos".

Desafortunadamente, muchos lectores no consideran estos apéndices como elementos de la novela y en ocasiones han sido ignorados. Para subsanar esta deficiencia, Christopher 
Tolkien se dio a la tarea de compilar, organizar y buscar la publicación de todas las obras inconclusas de su padre, a partir de su muerte, el 2 de septiembre de 1973. Entre éstas se encuentra El Silmarilion, obra clave para entender el legendarium de Tolkien, apenas esbozado en las páginas de SDLA y de El Hobbit. Pero los detractores eran implacables: Martin Hagis (2009) rescata una entrevista a Jorge Luis Borges en la que éste señala el problema de la trilogía, criticando la manera en la que el lector se queda fuera de este universo debido a la falta de explicación (Burgin, 1998).

La mayoría de los "lectores contemporáneos" de estas historias conocieron la trama a partir de las películas de Peter Jackson (2001), que comenzaron a salir a la luz a partir de 2001. En estas películas ya se han sintetizado los detalles ocultos que se explican en los apéndices de SDLA, en la trama de El Silmarilion, en las Cartas de Tolkien y en Los cuentos inconclusos de Númenor y la Tierra Media. Para estos lectores, la información nueva se asimiló en tres instantes que invitarían a la lectura de las novelas posteriormente, y con la información ya asimilada, el disfrute y la opinión de la obra ha resultado muy diferente.

Sin embargo, múltiples críticas sobre la coherencia de la narrativa de Tolkien en pantalla se han mostrado a la par de las alabanzas a las producciones cinematográficas. Jannet Brennan Croft (2005) argumentó, rescatando lo que Tolkien había conceptualizado anteriormente como "anticipación" y "achatamiento", que la adaptación del guion realizada por Jackson se apresuraba y no enmarcaba en su totalidad la caracterización y el ritmo propuesto por Tolkien en sus novelas y que, por lo tanto, se revelaba demasiada información en poco tiempo. Esto comprueba el argumento anterior y la perspectiva dividida que provocó la adaptación al cine. No ahondaremos más en este punto, que no obstante invita a la reflexión.

\section{Sobre los personajes en el legendarium}

El Silmarilion es el génesis de las historias de la Tierra Media. La obra narra episodios que pareciesen baladas o epopeyas cuyo propósito es mantener en la memoria y en el corazón de la audiencia a los héroes en sus guerras (esta tradición pertenece a los elfos antiguos). El estilo es principalmente la narración en tercera persona de los eventos desde la creación del mundo; la caída de Melkor, quien es la primera personificación del mal; las migraciones de los elfos que se derivaron en diversos grupos étnicos, que luego tendrán un papel muy importante en el establecimiento del poder mayor; la aparición de los primeros hombres y sus alianzas con los elfos, y el trabajo hacendoso pero avaricioso de los enanos. Sin embargo, todas las narraciones, aunque inicialmente divergentes, se focalizan en la creación de las joyas más hermosas que se hubiesen creado jamás, los silmarils, que le dan nombre a la obra.

Los silmarils fueron creados por el príncipe elfo Fëanor, inicialmente aguerrido y leal pero quien, al observar la belleza de los silmarils, que reflejaban la luz de los Dos Árboles Sagrados de Valinor, el reino de los valar, se volvió avaro y se aisló de la compañía de sus hermanos. La

Año 17, núm. 41, marzo 2021

ISSN: 2007-1760 (impreso) 2448-9026 (digital) | DOI: 10.30973/inventio/2021.17.41/4 
historia de El Silmarilion explora los eventos de las épocas, desde el origen del universo hasta las múltiples guerras y desavenencias; por lo tanto, el propósito fundamental de esta obra es narrar, desde el inicio de los tiempos, las complicaciones e inherente disminución de la vida de los elfos sobre la Tierra Media.

La estructura de El Silmarilion comienza con la creación del universo en la Ainulindalë, la música de los ainür. En ella se narra cómo el ser supremo Eru llúvatar concibe la creación de los ainür, seres inmortales que son partícipes de la majestad de Eru en el Vacío del universo. Después, Eru concibe la música del universo, en la que se vislumbra la creación de Arda, el mundo que alberga la Tierra Media, y de los seres que la habitarán, y permite que los ainür participen de la construcción de esta sinfonía, ya que son seres que provienen del pensamiento de Eru y continuarán con la idea inicial que éste tendría. Sin embago, un ainür llamado Melkor es tentado a provocar una discordancia en la melodía. En medio de la sinfonía, Melkor logra que otros ainür, confundidos por el sonido, sigan su discordancia. Melkor se envanece de tal hazaña e incrementa el sonido; no obstante, Eru ha observado este desarrollo desde el inicio. Reprende a Melkor con la indicación de que él mismo ha permitido la discordancia, ya que ésta también es necesaria en la creación del universo y hace explícito el origen del mal, incluso antes de la formación de la Tierra Media. Según lo explica Tolkien en la Carta 212, esta inclusión permite que, subsecuentemente, se presenten en Eä diversos ejemplos de rebeliones y discordancias no como consecuencia del libre albredrío, sino como elemento natural dentro de Eä (Tolkien, 1995).

La mitología de Tolkien comienza cuando los ainür, que participaron en la creación de la melodía, son invitados por Eru para realizar la creación del universo a partir de la visión que provenía de esta música. Los ainür que participaron cambiaron su morada a Arda, un planeta ubicado en la vastedad inmensa de Eä, que albergaría la Tierra Media, la cual en un inicio estaba desordenada y era plana (Tolkien, 2002, pp. 12-20). Ellos serían los responsables de clasificar las notas para que produjesen la música inicial que Eru había concebido. También se les permitió adoptar la forma que quisieran, y es en esta sección en la que se observa más claramente el propósito de Tolkien sobre el establecimiento de dioses que manipulan elementos físicos observables.

Comienza, entonces, la segunda sección de EI Silmarilion, Ilamada Valaquenta o Historia de los Valar. En ella se reconocen los ainür, ahora llamados valar, que ocupan Arda, varón y hembra, en ocasiones en matrimonios perfectos: Manwë, señor de Arda, los vientos y las nubes, habita con Varda, dama de las estrellas; Aulë, el herrero especialista en gemas, cuya esposa es Yavanna, dadora de frutos y amante de todas las cosas que crecen en la tierra; Ulmo, que yace solo y domina los mares; Tulkas, el gran guerrero de los valar; Oromë, cazador y señor de los bosques, y su esposa, Vánadama, de las flores y pájaros y hermana menor de Yavanna. También se menciona a Nessa, Nïena, Lorien, Este, Vaire y Namo (Tolkien, 2002, pp. 
23-31). Tolkien también explica jerarquías dentro de estos grupos, ya que los maiar, conocidos inicialmente como istari, pese a ser seres inmortales, tenían un menor rango que los valar. Según su descripción, eran siervos de los valar y su número se desconoce; sin embargo, cumplían propósitos específicos y de gran importancia para el plan de Eru. Un maia que representa estas cualidades es Gandalf, en un inicio conocido como Olorín.

Asimismo, se describe el grupo de los enemigos o aquellos ainür que participaron en la discordancia creada por Melkor, ya sea con intención o engañados por él. Melkor declaró la guerra a los valar desde el inicio de los tiempos y cada obra que ellos realizaban, fueran montañas o valles, árboles o ríos, Melkor la destruía e hizo de la Tierra Media un lugar caótico e inestable, tal y como se imaginaría el inicio de la tierra sin habitante alguno. Durante la narración de El Silmarilion, Melkor está inmerso en un vaivén de interacciones con los valar. En un inicio es perdonado por sus faltas, pero cada vez se vuelve más arrogante y rehúsa humillarse ante sus hermanos para solicitar el perdón. Esta cualidad se hace más evidente a medida que Melkor reduce sus interacciones con los valar y las incrementa con los elfos.

Casi al final de El Silmarilion, el cual describe principalmente las acciones de Melkor, se menciona a Sauron, un maia servidor de Melkor desde el inicio, pero más malévolo y traicionero. El fin de Sauron se narra en SDLA, no así el de Melkor, posteriormente llamado Morgoth, quien fue encerrado por los valar en el Vacío del universo, de donde escapará en las edades futuras y una nueva batalla, la Dagor Dagorath o la Última Batalla, dará fin al mundo conocido; sin embargo, éste será reconstruido nuevamente por los ainür y los hijos de llúvatar en perfecta armonía.

Esta batalla se menciona cuatro veces en El Silmarilion. La primera mención se refiere a la revelación que permitirá mostrar el propósito de los enanos como creación de Aulë, quienes ayudan en la formación de la nueva Arda después de esta batalla y mediante la cual podrán ser considerados hijos de llúvatar (Tolkien, 1979, p. 39). Esta revelación se menciona también como una señal en el firmamento, establecida por Varda con el diseño de la constelación Menelmacar, o en Síndar, El Espadachin del Cielo, constelación que también enmarcaría la llegada de los elfos (Tolkien, 1979, p. 45). Finalmente, se retoma explícitamente al indicar que, después del Fin, Fëanor será restituido y volverá a Arda, y todos los misterios, especialmente el de la belleza de los silmarils, serán revelados (Tolkien, 1979, p. 69). Adicionalmente, se hace referencia al destino de Ar-Pharazôn, último rey númenóreano, que rebeldemente intentó invadir Aman y, como castigo, él y su ejército fueron aprisionados en las Cuevas de los Olvidados, cuando el mismo Erú reconfiguró Arda como consecuencia de su desvarío (Tolkien, 1979, p. 334). Ar-Pharazôn tendrá en esta última batalla un papel aún no revelado.

Esta descripción es comparable a la estructura de algunos textos clásicos, como los de Ovidio (1999) o las Eddas nórdicas, en las que se dibuja el origen del universo y, en orden cronológico, la aparición de los hombres y las subsecuentes guerras y conflictos que ensalzaron 
héroes de los que fue necesario hablar en las gestas. Es incluso similar a la narración cristiana del Génesis, donde se indica que la tierra estaba desordenada y vacía. El Silmarilion imita la estructura de la epopeya clásica, pero escrita a inicios del siglo xx y con elementos que servirían para la creación de la novela fantástica. Sin embargo, describir el origen del universo y crear dioses, semidioses y razas diversas de seres que habitarían Arda, que eventualmente se convertiría en nuestra Tierra, es riesgoso si no existe una explicación de cómo un proceso llevaría al otro. Es por esto que el elemento principal que Tolkien usó para dar coherencia a su creación fue la invención, propósito y transformación del lenguaje.

\section{Sobre el lenguaje}

Tolkien consideraba que el lenguaje se fortalecía y permanecía en relación con la identidad que se pudiese desarrollar con los ejemplos de héroes antiguos y linajes reales. El lenguaje es, entonces, el instrumento más efectivo para dar a conocer los fundamentos de su ideología. Foucault (2005) expresó que "ciertos tipos de enunciación vinculan a ciertos individuos" (p. 44). Es entonces posible analizar los grupos de diferentes elfos bajo esta premisa.

Inicialmente sólo existía un tipo de elfos que aparecieron en la región llamada Cuiviénen. al este de la Tierra Media (Tolkien, 1979, p. 43). En el inicio, Eru llúvatar permitió que los valar esperaran el momento en que despertaran los hijos de llúvatar, que son los elfos, o los primeros nacidos, y posteriormente los hombres. Esto indica que los elfos, como los hombres, fueron creados por llúvatar, pero ayudados en su recorrido en la Tierra Media por los valar, y los cuales, de manera más cercana a las descripciones mitológicas, poseían inmortalidad según la duración de Eä. Cuando los elfos despertaron, los valar quisieron que habitaran con ellos en las tierras altas de Valinor, el reino de los dioses.

Entonces, los valar hablaron sobre las bondades del continente de Aman, también conocido como el Reino Bendecido y las Tierras Imperecederas, localizado al oeste de la Tierra Media. Si los elfos aceptaban iniciar el viaje, era necesario dejar los bosques conocidos, cruzar las tierras inhóspitas, navegar por el mar y nunca más volver. La promesa era la perfecta interacción de los valar y los elfos, así como las bondades que esto supondría, el conocimiento y la pureza que los enmarcaría. Pero no todos los elfos fueron convencidos y entonces empezó su división. Sanacore (2015) explica que los elfos se denominan quendi, y éstos se dividen en eldar, o aquellos que tomaron el gran viaje a Aman, y avari, o los que reusarón dejar el lugar en el este, donde aparecieron por primera vez. También se dividen principalemente en elfos de luz y elfos de oscuridad. Esta denominación se determina según los elfos que contemplaron la luz de los Dos Árboles Divinos que iluminaban Valinor, la tierra de los valar, y los elfos que no lograron o desistieron llegar a esta región.

Así, los elfos comenzaron su travesía. Después de que los valar hubiesen invitado a tres representates para conocer Valinor y presentarse como embajadores antes sus familias en 
la Tierra Media, tres familias reales comenzaron el viaje: vanyar, nöldor y teleri. Los vanyar, liderados por Ingwë, alcanzaron la meta de llegar a Valinor y nunca más volvieron a la Tierra Media. Los nöldor, liderados por Finwë, asumen una participación determinante en el desarrollo de los eventos de El Silmarilion, al ser el grupo de elfos exiliados de Valinor. Finalmente, los teleri se caracterizaron por distraerse y detenerse durante el recorrido debido a la belleza de los ríos, las montañas y los bosques (Tolkien, 1979, pp. 50-51). Hasta este punto, Tolkien ha determinado que estos grupos sigan una monarquía innata o la establecida por aquellos que despertaron primero. Sin embargo, la clasificación más importante es la de los elfos de luz, calaquendi, o aquellos que llegaron a Aman y observaron la luz de los Dos Árboles, y los elfos de oscuridad, moriquendi, o aquellos que nunca observaron la luz antes de la creación de la Luna (Tolkien, 1979, p. 51).

Durante el recorrido, en el grupo de los teleri, Lenwë se opuso a continuar, al reconocer la belleza del río Anduin. Con un grupo de otros teleri, permanecieron en los bosques alrededor del Anduin y fueron luego conocidos como los elfos verdes, elfos del Bosque Oscuro o silvanos de Lothlórien, sin confundirlos con los liderados posteriormente por Celeborn y Galadriel, dama nöldor que fue exiliada de Valinor. Uno de los elfos verdes más prominentes es Legolas, hijo del rey Thranduil, personaje clave perteneciente a la Comunidad del Anillo.

Durante la migración se presentó una complicación mayor. Uno de los reyes teleri, Elwë, después de haberse reunido con su amigo Finwë, deambuló por el bosque de Nan Elmoth, en la región de Belerian. Aquí se encontró con Melian, la maia de la cual se enamoró y por la que permaneció absorto en largo silencio. Se ocultaron de los demás y algunos de su pueblo se reusaron a continuar. Después de doscientos años, Elwë y Melian se revelan y forman el reino de Doriath en conjunto con los elfos leales que permanecieron en espera. Esto dio origen al grupo de los Ilamados elfos grises o sindar. Elwë también sería conocido a partir de este momento como Thingol; sin embargo, jamás perdería su estatus de Alto Elfo, al haber sido embajador de los valar antes de la migración (Tolkien, 1979, pp. 54-55).

Según Nietzsche (2009), la manera en que cada uno recibe el lenguaje determina lo que podremos lograr con él y, por lo tanto, determina lo que creemos. Retomando la escena anterior, los elfos que sí logran llegar a la tierra prometida y que residen en ese lugar perfecto también interactúan con los dioses y, por lo tanto, su lenguaje refleja esta superioridad. El sonido de las palabras es más armonioso y solemne, como lo explica Tolkien en los apéndices de SDLA. Eventualmente, estos Altos Elfos, llamados nöldor, regresan a la Tierra Media y llevan su lenguaje solemne, con el que tendrán que interactuar con los elfos que permanecieron en las profundidades de los bosques, testigos de la maldad que se estaba desarrollando en las tierras oscuras. Obviamente, el lenguaje de los elfos grises o sindar, nombre utilizado por los nöldor para referirse a los elfos que permanecieron en la Tierra Media y que encontraron a su regreso a ésta, es más práctico, mucho menos solemne pero útil. Y mientras las 
edades pasaban, el reconocimiento de ese lenguaje solemne era la indicación de que alguna vez existió amistad entre elfos y dioses, y esto supondría un beneficio mayor para enfrentar cualquier tipo de problema que pudiese surgir. El lenguaje es espejo de la benevolencia del pasado y profeta de la protección futura, al menos para aquellos que tengan oídos para oír.

Para ejemplificar sólo un aspecto mínimo del proceso de desarrollo de lenguajes retomemos a Foucault (2005), quien indica, con su concepto de ritualización del habla, la identificación de sujetos que emiten ciertos mensajes, creando así sociedades de discurso. En SDLA YEI Silmarilion, identificar el lenguaje usado proporciona elementos de análisis sobre la ideología de los personajes. El lenguaje de los Altos Elfos es quenya, como la clasificación de los elfos que llegaron a Aman, lenguaje desarrollado en Valinor, la tierra de los dioses. Tiene una pronunciación delicada y es de naturaleza metafórica. En la Tierra Media, los nöldor eventualmente adoptaron el lenguaje sindarin, que originalmente pertenecía a los elfos grises, que no completaron su viaje a Aman y que formaron reinos en Belerian, subcontinente situado al noroeste de la Tierra Media. Alternativamente, el quenya devino en una lengua culta y sin uso cotidiano. Sin embargo, ambos son lenguajes orales, ya que la forma escrita se denomina tengwar y fue desarrollada por Fëanor (Tolkien, 1979, p. 70), quien sí viajó a Aman y luego se trasladó a la Tierra Media durante el exilio de los nöldor.

Por parte de los enemigos, el ejemplo simple se encuentra en los orcos, quienes no poseen un lenguaje determinado, solamente una burda articulación de sonidos (Tolkien, 2012, p. 1105). Los orcos odian su propio lenguaje porque es rudo y sin melodía y prefieren no hablar, sino actuar. El discurso entonces, según Foucault (2005), es una "violencia que se ejerce sobre las cosas como una práctica" (p. 53). De acuerdo con lo anterior, los orcos están sujetos al dominio de un dispositivo de poder establecido a través de aquellos que sí usan el lenguaje, como Saruman, quien denomina uruk-hai a su raza modificada de orcos - literalmente traducido del sindarin como "orcos" - y al resto, snaga o esclavos. En el Apéndice F, bajo la subdivisión de Otras Razas, se indica que los orcos no tenían un lenguaje propio, sino que tomaban elementos de otros lenguajes y los pervertían a su gusto (o disgusto), y a través del lenguaje se mostraba el odio que sentían no sólo por otras razas, sino también por ellos mismos.

No obstante, Tolkien expresa en la Carta 212 que la finalidad de SDLA no es mostrar un despliegue de poder, sino la observancia de la muerte, la inmortalidad y la memoria por sobre todas las cosas. Lo anterior se hace explícito en la escritura en runas de la página inicial de SDLA, que muestra un marco con dos leyendas: la leyenda superior, escrita en cirth, el estilo usado en la Tierra Media, que representa los sonidos sindarin, la cual se traduce al inglés como "El Señor de los Anillos traducido del Libro Rojo", y la leyenda inferior, escrita en tengwar, y traducida como "de la Periannath realizado por John Ronald Reuel Tolkien. A partir de este punto se describe la historia de la Guerra del Anillo y el Retorno del Rey como fue atestiguado por los hobbits" (Tolkien, 2012, pp. 1, 1088-1100).

Año 17, núm. 41, marzo 2021

ISSN: 2007-1760 (impreso) 2448-9026 (digital) | DOI: 10.30973/inventio/2021.17.41/4 
De la misma manera, la impresión de El Silmarilion muestra un marco similar al escrito en tengwar. El comunicado oficial difundido por Christopher Tolkien indicaba que esta inscripción no tenía ningún propósito en particular. Sin embargo, debido al interés popular que se observa a través de las comunidades virtuales, se ha logrado la traducción y edición de dicha leyenda con base en la información de los Apéndices E y F. El texto dice: “La historia de la Primera Edad cuando aún Morgoth habitaba la Tierra Media y de cómo los Elfos lo enfrentaron en batalla para recuperar los Silmarils/a la cual se han añadido la Caída de Númenor y la historia de los anillos de poder y la Primera Edad cuando estas historias llegaron a su fin" (Tolkien, 1979, p. 1).

En los relatos de Tolkien, las gestas peleadas anteriormente sirven para enseñar a los nuevos guerreros. Como se narra en EI Silmarilion y SDLA, el momento de la batalla pasó a ser historia, y la historia a mito, y así el mito fue olvidado. Sin embargo, en el momento en que la maldad resurgió se debieron buscar ecos de ese discurso olvidado para entender lo que sucedía en ese momento nuevo, y no sólo para hacer lógico el proceso, sino para obtener herramientas que los ayudaran a salir victoriosos. Ahora bien, esto muestra cierta coacción que se produce por ese discurso arcaico: sólo el entendido, el educado, podrá comunicar lo que se pretende; de otra manera, el discurso permanecerá inútil. Es entonces esencial la figura de Gandalf para establecer la correlación entre los tiempos antiguos y el momento presente.

\section{Conclusión}

Para concluir, es necesario retomar la idea de que todos los mundos creados son un discurso, y que los personajes hablan de la cosmovisión del autor. Todos los mundos retratados en los libros están formados por realidad e imaginario, el tiempo y el espacio de su creador, y el imaginario del cual él también formaba parte. Para Tolkien, la cualidad principal para la creación de las diferentes razas con sus respectivas ideologías yacía en el origen y uso del lenguaje. De esta manera, El Silmarilion se convierte en el origen ideológico de los elfos, al describir la evolución del lenguaje en correlación con los asentamientos de los diversos grupos de elfos. A su vez, SDLA retoma un análisis del lenguaje que proviene de la mente del autor y se muestra a manera de apéndice académico al libro ficticio llamado Libro Rojo de Westmarch o de la Periannath. Lo anterior se debe a que El Silmarilion fue publicado de manera póstuma; por lo tanto, la audiencia de SDLA aún no estaba familiarizada con tales explicaciones.

Este análisis abre futuras posibilidades de exploración. En primera instancia, el acercamiento al tratamiendo de Tolkien como académico, quien recibe un manuscrito antiguo del cual traduce la historia de $S D L A$, nos permite establecer la hipótesis sobre la fundamentación mitológica que el autor buscaba con tanto ahínco. En segunda instancia, sería pertinente considerar cómo un lector contemporáneo lee a Tolkien, a pesar de las inferencias medievales, cómo se define el texto en su interacción con el receptor, y cómo funciona el texto y su 
recepción, al observar las interacciones contemporáneas en la búsqueda de significados de los elementos crípticos en las historias del legendarium. En la actualidad contamos ya con las referencias cruzadas para hacer una lectura más profunda de Tolkien y así tener una visión completa de este universo creado, que se sustenta en elementos observables, como los personajes y el lenguaje. De esta manera se percibe una vitalidad en la narración, ya que la evolución de ambos proporcionará profundidad a la historia.

\section{Referencias}

Burgin, R. (ed.) (1998). Jorge Luis Borges: Conversations. University Press of Mississippi.

Croft, J. B. (2005). Mithril Coats and Tin Ears: 'Anticipation' and 'Flattening' in Peter Jackson's The Lord of the Rings Trilogy. En Jannet Brennan (Ed.), Tolkien on Film: Essays on Peter Jackson's The Lord of the Rings (pp. 63-80). Mythopoeic Press.

Foucault, M. (2005). El Orden del Discurso (p. 44). Cloter-Tusquets.

Hagis, M. (2009). Prodigios y Ficciones: Coincidencias y desencuentros entre Borges y Tolkien. Hispanoamérica, 38 (112). 115-121. https://www.jstor.org/stable/27809451

Herrero-Gil, M. (2008). Introducción a las teorías del imaginario. Entre la ciencia y la mística. Ilu. Revista de Ciencia de las Religiones, 13. 241-258. https://revistas.ucm.es/index.php/ ILUR/article/view/ILURo808440241A

Jackson, P. (dir.) (2001). El Señor de los Anillos: La Comunidad del Anillo. New Line Cinema.

Jakobsson, A. (2009). Talk to the Dragon: Tolkien as a Translator. Tolkien Studies, 6. 27-39. https:// doi.org/10.1353/tks.0.0053

Nietzsche, F. (2009). Obras Nietzsche I. Estudio introductorio de German Cano. Gredos.

Ovidio (1999). Las metamorfosis (pp. 17-26). Edicomunicación.

Pagán, S. (2017). Libros Poéticos y Sapienciales. Interpretación eficaz hoy. Editorial Clie.

Sanacore, D. (2015). The Norse Myth in the world of Tolkien (pp. 1-36). [Tesis Corso Di Laure in Lingue e Culture Moderne] Università degli Studi di Pavia.

Shippey, T. (2000). J. R. R. Tolkien: Author of the Century. Harper.

Tolkien, J. R. R. (1979). Quenta Silmarillion. Of Aulë and Yavanna. En Christopher Tolkien (Ed.), The Silmarillion. Ballantine Books.

Tolkien, J. R. R. (1995). Carta 212. En Humphrey Carpenter y Christopher Tolkien (Eds.), The Letters of J. R. R. Tolkien (pp. 285-286). Houghton Mifflin Harcourt.

Tolkien, J. R. R. (2004). The Lord of the Rings: $50^{\text {th }}$ Anniversary Edition. Houghton Mifflin Harcourt. Tolkien, J. R. R. (2012). The Return of the King. Houghton Mifflin Harcourt.

Año 17, núm. 41, marzo 2021 